\title{
Association between renal function and platelet reactivity during aspirin therapy in elderly patients with atherosclerotic cardiovascular disease
}

\author{
Wenyi Liang, Peng Zhang and Meilin Liu* (D)
}

\begin{abstract}
Background: Aspirin is the key treatment in the secondary prevention of atherosclerotic cardiovascular disease. High on-treatment platelet reactivity (HTPR) to aspirin has been reported to partially account for the enhanced risk of thrombotic events. In particular, HTPR has been described more frequently among elderly patients. The aim of this study was to identify the clinical and biological factors associated with HTPR in a real-life elderly population.

Methods: In this retrospective study, elderly patients with atherosclerotic cardiovascular disease on regular aspirin treatment were enrolled. Cardiovascular risk factors, routine biological parameters, comorbidities, and concomitant medications were recorded. The upper quartile of the platelet aggregation rate, determined by light transmission aggregometry with arachidonic acid, was defined as the HTPR group.

Results: A total of 304 patients were included (mean age $77 \pm 8$ years, $76 \%$ men). Patients in the HTPR group were older than the patients in the non-HTPR group (mean age: $79 \pm 7$ vs. $76 \pm 8$ years, $p=0.008$ ). Patients with moderately decreased estimated glomerular filtration rate (eGFR) had a higher frequency of HTPR than patients with slightly decreased eGFR or normal eGFR (35.8, 22.5, 12.2\%, respectively, $p<0.05)$. In multivariate analysis, an independent risk factor for HTPR was the eGFR (OR: 0.984, 95\% Cl: 0.980-0.988, $p<0.001$ ).
\end{abstract}

Conclusions: Advanced age and decreased eGFR are correlated with poor pharmacodynamic response to aspirin.

Keywords: Age, Aspirin, Atherosclerotic cardiovascular disease, Platelet reactivity, Renal function

\section{Background}

Atherosclerotic cardiovascular disease (ASCVD) includes coronary heart disease, ischemic stroke or transient ischemic attacks, and peripheral arterial disease, all of presumed atherosclerotic origin [1]. Aspirin is the key treatment in the secondary prevention of ASCVD due to its prominent antiplatelet effects [2,3]. Aspirin impedes thrombus formation by inhibiting cyclooxygenase

\footnotetext{
* Correspondence: liumeilin@hotmail.com

Department of Geriatrics, Peking University First Hospital, No. 8, Xishiku Street, Xicheng District, Beijing 100034, People's Republic of China
}

(COX)-1, which mediates thromboxane A2 (TXA2) synthesis $[4,5]$.

Recent studies have shown that aspirin fails to prevent a number of serious cardiovascular events among highrisk patients $[6,7]$. This has led to the introduction of the concept of high on-treatment platelet reactivity (HTPR) [8]. In particular, HTPR has been described more frequently among elderly patients, conditioned by impaired drug absorption and metabolism and by a baseline of more enhanced platelet reactivity. Most previous studies enrolled patients receiving dual antiplatelet therapy $[9,10]$. However, there is evidence of overlap in

(C) The Author(s). 2021 Open Access This article is licensed under a Creative Commons Attribution 4.0 International License, which permits use, sharing, adaptation, distribution and reproduction in any medium or format, as long as you give appropriate credit to the original author(s) and the source, provide a link to the Creative Commons licence, and indicate if changes were made. The images or other third party material in this article are included in the article's Creative Commons licence, unless indicated otherwise in a credit line to the material. If material is not included in the article's Creative Commons licence and your intended use is not permitted by statutory regulation or exceeds the permitted use, you will need to obtain permission directly from the copyright holder. To view a copy of this licence, visit http://creativecommons.org/licenses/by/4.0/ The Creative Commons Public Domain Dedication waiver (http://creativecommons.org/publicdomain/zero/1.0/) applies to the data made available in this article, unless otherwise stated in a credit line to the data. 
the antiplatelet effects of aspirin and P2Y12 antagonists [11]. The main objective of our study was to identify routinely available clinical and biological factors associated with HTPR in a real-life elderly population of ASCVD patients receiving aspirin as monotherapy. We hypothesized that finding factors associated with HTPR can help identify high-risk patients and eventually modify antiplatelet therapy.

\section{Methods}

\section{Study design and participants}

Elderly patients on regular aspirin treatment in the Department of Geriatrics of Peking University First Hospital were enrolled from March 2014 to December 2019.

The inclusion criteria were as follows:

1. Age: $\geq 60$ years;

2. Diagnosis of ASCVD, presence of at least one of the following diseases: coronary heart disease, ischemic stroke, transient ischemic attacks, and peripheral arterial disease;

3. Aspirin monotherapy was used for secondary prevention (50-100 mg daily for more than 1 month) without a change in dose within the previous month. Compliance with aspirin was verified separately by the patient's attending physician and study physician.

The exclusion criteria were as follows:

1. Use of other antithrombotic medications (including clopidogrel, ticagrelor, prasugrel, dipyridamole, warfarin, heparin, low-molecular-weight heparin and new oral anticoagulants) or nonsteroidal antiinflammatory drugs within 1 month;

2. Severe renal dysfunction [estimated glomerular filtration rate $(\mathrm{eGFR})<30 \mathrm{ml} / \mathrm{min} / 1.73 \mathrm{~m}^{2}$ ] or dialysis;

3. Platelet count $<100 \times 10^{3} / \mu \mathrm{L}$ or $>450 \times 10^{3} / \mu \mathrm{L}$;

4. A major surgical procedure or severe inflammation within 1 week;

5. History of malignant tumor, chronic inflammatory diseases, serious liver disease and autoimmune disease.

\section{Medical records collection}

For each patient, detailed medical records were obtained from the electronic medical record system, including age, sex, smoking habit, alcohol habit, body mass index, comorbidities, concomitant medications, and usual biological parameters.

\section{Platelet reactivity}

For each patient, platelet aggregation was determined by light transmission aggregometry with arachidonic acid
(LTA-AA). Platelet aggregation tests have been routinely performed for several years at our clinical laboratory by experienced technicians. Blood samples were collected within 21-22 $\mathrm{h}$ after aspirin intake and analyzed within $1 \mathrm{~h}$ from collection. Blood samples anticoagulated with $3.2 \%$ sodium citrate were centrifuged at $200 \times g$ for 10 min to obtain platelet-rich plasma and further centrifuged at $2000 \times g$ for $10 \mathrm{~min}$ to obtain platelet-poor plasma. Platelet aggregation was performed by the addition of $0.5 \mathrm{mg} / \mathrm{mL}$ arachidonic acid to platelet-rich plasma cuvette using platelet-poor plasma as a reference cuvette. The percentage of platelet aggregation was defined as the maximal light transmittance after arachidonic acid addition measured by the LBY-NJ4 platelet aggregometer (PRECIL, Beijing, China) [12].

\section{Patient group}

Patients were divided according to LTA-AA. Patients with platelet aggregation rates in quartile IV were defined as the HTPR group, whereas patients with platelet aggregation rates in quartiles I-III were defined as the non-HTPR group.

Patients were also stratified by eGFR, which was calculated using the MDRD (Modification of Diet in Renal Disease) formula [13]. The G1 group included patients with normal eGFR (eGFR $\geq 90 \mathrm{~mL} / \mathrm{min} / 1.73 \mathrm{~m}^{2}$ ). The G2 group included patients with slightly decreased eGFR (eGFR $60-89 \mathrm{~mL} / \mathrm{min} / 1.73 \mathrm{~m}^{2}$ ). The G3 group included patients with moderately decreased eGFR (eGFR 30-59 $\mathrm{mL} / \mathrm{min} / 1.73 \mathrm{~m}^{2}$ ).

\section{Statistical analysis}

The distribution normality of each variable was tested using the Kolmogorov-Smirnov test. Continuous variables were expressed as the mean $\pm \mathrm{SD}$ or median (interquartile range). Homogeneity of variance was tested for continuous variables. For normally distributed data, comparisons between two groups were performed by Student's unpaired $t$ test, and comparisons among groups were performed using one-way ANOVA, followed by post-hoc analysis of LSD tests (if variances were equal) or Tamhane's T2 tests (if variances were unequal). The nonparametric Mann-Whitney $U$ test or Kruskal-Wallis $\mathrm{H}$ test were performed if the data were nonnormal. Categorical variables were described as counts (percentages) and were tested using the chisquare test. Correction for multiple comparisons was performed using the Bonferroni-Holm correction. Correlations between quantitative variables were assessed using Pearson or Spearman correlation coefficients, as appropriate. Multivariate logistic regression analysis (forward: conditional) was performed to investigate risk factors for HTPR. After univariate analysis, variables that presented significant associations with HTPR $(p<0.10)$ 
were entered in the multivariate model. Differences were considered significant when $p<0.05$ (two-tailed). The cutoff value was calculated by analyzing the receiver operating characteristic (ROC) curve. Statistical analysis was carried out using SPSS version 16.0 software (SPSS Inc., Chicago, IL, USA).

\section{Results}

Finally, 304 patients with sufficient available clinical and biological information were selected for this study. The average age was $77 \pm 8$ years, and $233(76.6 \%)$ patients were males. There were 120 (39.5\%) patients with age $\geq$ 80 years and $8(2.6 \%)$ patients with age $\geq 90$ years.

\section{Testing of platelet aggregation}

During aspirin therapy, the range of LTA-AA was from 0.84 to $34.91 \%$, with a median value of $9.69 \%$ (IQR 6.80 $12.38 \%)$. There were $3(0.99 \%)$ patients with LTA-AA > $20 \%$. According to the aforementioned definition, there were 76 patients in the HTPR group (LTA-AA $\geq 12.38 \%$ ), with a median value of $14.41 \%$ (IQR 12.94 $16.82 \%$ ), and there were 228 patients in the non-HTPR group (LTA-AA $<12.38 \%$ ), with a median value of $8.69 \%$ (IQR 5.83-10.48\%).

\section{Clinical features of elderly patients with ASCVD classified by HTPR}

The clinical and biological characteristics of the study participants divided according to HTPR are shown in Table 1 and Table 2. Patients in the HTPR group were older than patients in the non-HTPR group (mean age: $79 \pm 7$ vs. $76 \pm 8$ years, $p=0.008$ ). In terms of the ASCV D spectrum, patients in the HTPR group had an increased presence of ischemic stroke or transient ischemic attacks, and fewer patients had a history of coronary heart disease than those in the non-HTPR group $(p<0.01)$. The ratio of angiotensin converting enzyme inhibitors/angiotensin receptor blockers (ACEIs/ARBs) medications was higher in the HTPR group $(p=0.046)$. There were no significant differences in daily aspirin

Table 1 Clinical characteristics of study participants classified by HTPR

\begin{tabular}{|c|c|c|c|}
\hline Variables & HTPR group $(N=76)$ & non-HTPR group $(N=228)$ & $p$ value \\
\hline Age, years & $79 \pm 7$ & $76 \pm 8$ & 0.008 \\
\hline Male sex, $n(\%)$ & $54(71.1)$ & $179(78.5)$ & 0.183 \\
\hline Body mass index, $\mathrm{kg} / \mathrm{m}^{2}$ & $24.0 \pm 2.7$ & $24.6 \pm 3.1$ & 0.149 \\
\hline Systolic blood pressure, $\mathrm{mmHg}$ & $138 \pm 18$ & $134 \pm 16$ & 0.076 \\
\hline Diastolic blood pressure, $\mathrm{mmHg}$ & $71 \pm 11$ & $73 \pm 11$ & 0.164 \\
\hline \multicolumn{4}{|l|}{ Medical history } \\
\hline Coronary heart disease, $n$ (\%) & $59(77.6)$ & $210(92.1)$ & 0.001 \\
\hline $\mathrm{PCl}, n(\%)$ & $33(43.4)$ & $115(50.4)$ & 0.289 \\
\hline Ischemic stroke or TIA, n (\%) & $39(51.3)$ & $56(24.6)$ & $<0.001$ \\
\hline Peripheral artery stenosis, $n(\%)$ & $7(9.2)$ & $29(12.7)$ & 0.412 \\
\hline Hypertension, $n(\%)$ & $63(80.8)$ & $175(75.1)$ & 0.307 \\
\hline Diabetes mellitus, $n(\%)$ & $24(31.6)$ & $75(32.9)$ & 0.832 \\
\hline Hyperlipidemia, $n(\%)$ & $69(90.8)$ & $191(83.8)$ & 0.132 \\
\hline Smoking habits: former/current, $n(\%)$ & $17 / 8(22.4 / 10.5)$ & $66 / 25(28.9 / 11.0)$ & 0.505 \\
\hline Alcoholic habits: former/current, $n$ (\%) & $5 / 5(6.5 / 6.5)$ & $22 / 28(9.6 / 12.3)$ & 0.239 \\
\hline \multicolumn{4}{|l|}{ Daily aspirin dose } \\
\hline 100 mg, n (\%) & $65(85.5)$ & $196(86.0)$ & 0.924 \\
\hline $50 \mathrm{mg}$ or $75 \mathrm{mg}, n(\%)$ & $11(14.5)$ & $32(14.0)$ & \\
\hline \multicolumn{4}{|l|}{ Medications taken } \\
\hline ACEIs/ARBs, $n(\%)$ & $48(63.2)$ & $114(50.0)$ & 0.046 \\
\hline Calcium-channel blockers, $n$ (\%) & $24(31.6)$ & $85(37.3)$ & 0.369 \\
\hline$\beta$-blockers, $n(\%)$ & $53(69.7)$ & $146(64.0)$ & 0.365 \\
\hline Nitrates, n (\%) & $31(40.8)$ & $68(29.8)$ & 0.077 \\
\hline Statins, $n(\%)$ & $72(94.7)$ & $202(88.6)$ & 0.120 \\
\hline Diuretics, n (\%) & $11(14.5)$ & $33(14.5)$ & 0.999 \\
\hline Proton pump inhibitors, $n$ (\%) & $21(27.6)$ & $41(18.0)$ & 0.071 \\
\hline
\end{tabular}

PCI Percutaneous coronary interventionm, TIA Transient ischemic attacks, ACEls Angiotensin converting enzyme inhibitors, ARBs Angiotensin receptor blockers 
Table 2 Laboratory data of study participants classified by HTPR

\begin{tabular}{llll}
\hline Variables & HTPR group $(\boldsymbol{N}=\mathbf{7 6})$ & non-HTPR group $(\boldsymbol{N}=\mathbf{2 2 8})$ & $\boldsymbol{p}$ value \\
\hline Hemoglobin, $\mathrm{g} / \mathrm{dl}$ & $12.6 \pm 1.6$ & $13.4 \pm 1.6$ & $<0.001$ \\
White blood cell count, $\times 10^{3} / \mathrm{\mu L}$ & $5.9 \pm 1.8$ & $6.1 \pm 1.5$ & 0.458 \\
Neutrophil percentage, $\%$ & $61.3 \pm 10.9$ & $62.1 \pm 9.5$ & 0.507 \\
Platelet count, $\times 10^{3} / \mathrm{uL}$ & $174 \pm 49$ & $184 \pm 51$ & 0.180 \\
Mean platelet volume, fl & $8.7 \pm 0.8$ & $8.8 \pm 1.2$ & 0.334 \\
eGFR, $\mathrm{mL} / \mathrm{min} / 1.73 \mathrm{~m}^{2}$ & $65.2 \pm 14.7$ & $71.8 \pm 17.3$ & 0.002 \\
Serum uric acid, $\mathrm{mg} / \mathrm{dL}$ & $5.83 \pm 1.46$ & $5.55 \pm 1.27$ & 0.112 \\
Serum creatinine, $\mathrm{mg} / \mathrm{dL}$ & $1.00(0.86-1.17)$ & $0.98(0.81-1.12)$ & 0.121 \\
Serum urea, $\mathrm{mg} / \mathrm{dL}$ & $39.97 \pm 11.42$ & $40.99 \pm 12.92$ & 0.556 \\
Glycosylated hemoglobin, \% & $5.9(5.6-6.7)$ & $6.0(5.6-6.3)$ & 0.905 \\
Triglycerides, $\mathrm{mg} / \mathrm{dL}$ & $94.8(72.7-130.9)$ & $102.8(71.8-147.1)$ & 0.436 \\
Total cholesterol, mg/dL & $133.0(113.7-154.2)$ & $132.7(120.2-152.7)$ & 0.510 \\
HDL-C, mg/dL & $41.2 \pm 10.8$ & $42.9 \pm 10.5$ & 0.243 \\
LDL-C, mg/dL & $68.2(59.5-82.2)$ & $70.0(59.9-83.1)$ & 0.666 \\
C-reactive protein, mg/L & $0.98(0.32-3.90)$ & $0.73(0.35-1.70)$ & 0.389 \\
\hline
\end{tabular}

eGFR Estimated glomerular filtration rate, HDL-C High density lipoprotein cholesterolm, LDL-C Low density lipoprotein cholesterol

dose between the two groups $(p>0.05)$. Patients in the HTPR group had lower levels of eGFR (average values: 65.2 vs. $71.8 \mathrm{~mL} / \mathrm{min} / 1.73 \mathrm{~m}^{2}, p=0.002$ ), indicating poorer renal function than patients in the non-HTPR group. The hemoglobin level was significantly lower in the HTPR group than that in the non-HTPR group $(p<0.001)$.

Linear correlation analysis showed that LTA-AA was significantly correlated with age $(r=0.128, p=0.025)$, hemoglobin $(r=-0.216, p<0.001)$ and eGFR $(r=-0.230$, $p<0.001)$ for the entire study population. Multivariate regression analysis of HTPR included the following independent variables in the model: age, systolic blood pressure, eGFR, hemoglobin, nitrate use, proton pump inhibitor (PPI) use and ACEI/ARB use. The results showed that eGFR was an independent factor associated with HTPR (OR: 0.984, 95\% CI: 0.980-0.988, $p<0.001$ ).

\section{Clinical features of elderly patients with ASCVD classified by renal function}

Study participants were stratified by eGFR. Clinical and biologic characteristics with statistical significance are shown in Table 3. In all enrolled patients, $16.1 \%$ had a normal eGFR, 52.6\% had a slight decrease in eGFR, and $31.3 \%$ had a moderate decrease in eGFR. LTA-AA was higher in patients with decreased eGFR than in those with normal eGFR. Patients with moderately decreased eGFR had a higher frequency of HTPR than patients with slightly decreased eGFR or normal eGFR (35.8, $22.5,12.2 \%$, respectively, $p<0.05)$. Renal function deteriorates with age. As eGFR decreased, a descending trend of diastolic blood pressure levels and hemoglobin levels, as well as an ascending trend of serum creatinine, urea and uric acid levels appeared. Patients with moderately decreased eGFR had higher MPV (mean platelet volume)/PLT (platelet count) ratios and neutrophil percentages compared to those with slightly decreased eGFR $(p<0.05)$. Compared with patients with normal eGFR, patients with moderately decreased eGFR had an increased presence of ischemic stroke/transient ischemic attack, peripheral artery stenosis and hyperlipidemia $(p<0.05)$, and the ratios of ACEIs/ARBs, statins and PPI medications were higher $(p<0.05)$. The results of ROC analysis showed that eGFR levels in all patients were calculated with $70.3 \mathrm{~mL} / \mathrm{min} / 1.73 \mathrm{~m}^{2}$ as a cutoff value to predict HTPR, with an area under the ROC curve of 0.620 (95\% CI 0.551-0.689, $p=0.002$ ).

\section{Discussion}

Cardiovascular disease and thrombosis are very common complications in patients with renal dysfunction, possibly due to increased platelet activity. In the present study, we reported an association between HTPR and impaired renal function (using the surrogate of eGFR). Our study revealed that decreased eGFR was an independent risk factor of HTPR. HTPR was more common in elderly patients with mildly/moderately decreased eGFR than in those with preserved renal function. Therefore, we suggested that in elderly patients with impaired renal function undergoing aspirin therapy, platelet reactivity should be monitored more intensely to identify HTPR. In clinical practice, the personalized antithrombotic regimen, rather than routine use of aspirin, should be recommended in elderly patients with renal dysfunction. 
Table 3 Clinical features of study participants classified by renal function

\begin{tabular}{|c|c|c|c|c|c|c|c|}
\hline \multirow[t]{2}{*}{ Variables } & \multirow{2}{*}{$\begin{array}{l}\text { G1 group } \\
(N=49 ; \text { eGFR } \\
\geq 90 \mathrm{~mL} / \mathrm{min} / \\
\left.1.73 \mathrm{~m}^{2}\right)\end{array}$} & \multirow{2}{*}{$\begin{array}{l}\text { G2 group } \\
(N=160 ; \\
\text { eGFR } 60-89 \\
\mathrm{~mL} / \mathrm{min} / 1.73 \\
\left.\mathrm{~m}^{2}\right)\end{array}$} & \multirow{2}{*}{$\begin{array}{l}\text { G3 group } \\
(N=95 ; \text { eGFR } \\
30-59 \mathrm{~mL} / \\
\left.\min / 1.73 \mathrm{~m}^{2}\right)\end{array}$} & \multirow{2}{*}{$\begin{array}{l}P \\
\text { value }\end{array}$} & \multicolumn{3}{|l|}{$P$ value } \\
\hline & & & & & G1 vs. G2 & G1 vs. G3 & G2 vs. G3 \\
\hline eGFR, $\mathrm{mL} / \mathrm{min} / 1.73 \mathrm{~m}^{2}$ & $94.5 \pm 7.3$ & $74.2 \pm 8.5$ & $50.8 \pm 7.9$ & $<0.001$ & $<0.001$ & $<0.001$ & $<0.001$ \\
\hline HTPR, $n(\%)$ & $6(12.2)$ & $36(22.5)$ & $34(35.8)$ & 0.005 & 0.117 & 0.003 & 0.021 \\
\hline LTA-AA, \% & $7.75 \pm 4.07$ & $9.90 \pm 3.83$ & $10.92 \pm 4.63$ & $<0.001$ & 0.002 & $<0.001$ & 0.058 \\
\hline Age, years & $67 \pm 7$ & $76 \pm 7$ & $82 \pm 5$ & $<0.001$ & $<0.001$ & $<0.001$ & $<0.001$ \\
\hline Diastolic blood pressure, $\mathrm{mmHg}$ & $77 \pm 11$ & $72 \pm 10$ & $69 \pm 10$ & $<0.001$ & 0.007 & $<0.001$ & 0.025 \\
\hline Hemoglobin, g/dl & $14.0 \pm 1.6$ & $13.4 \pm 1.4$ & $12.4 \pm 1.7$ & $<0.001$ & 0.013 & $<0.001$ & $<0.001$ \\
\hline Neutrophil percentage, \% & $61.1 \pm 10.2$ & $59.9 \pm 9.4$ & $65.6 \pm 9.6$ & $<0.001$ & 0.458 & 0.007 & $<0.001$ \\
\hline $\mathrm{PLT}, \times 10^{3} / \mathrm{uL}$ & $190 \pm 55$ & $186 \pm 50$ & $169 \pm 47$ & 0.012 & 0.626 & 0.016 & 0.008 \\
\hline$M P V, f l$ & $9.4 \pm 1.4$ & $8.6 \pm 1.1$ & $8.7 \pm 1.0$ & $<0.001$ & 0.004 & 0.016 & 0.886 \\
\hline MPV/PLT ratio, $\mathrm{fl} \times 10^{-3} \mathrm{uL}$ & $0.053 \pm 0.018$ & $0.050 \pm 0.016$ & $0.056 \pm 0.018$ & 0.031 & 0.248 & 0.393 & 0.009 \\
\hline Serum creatinine, mg/dL & $0.70(0.62-0.80)$ & $0.95(0.85-1.03)$ & $1.21(1.12-1.32)$ & $<0.001$ & $<0.001$ & $<0.001$ & $<0.001$ \\
\hline Serum urea, mg/dL & $31.9 \pm 8.0$ & $38.0 \pm 9.2$ & $47.0 \pm 14.7$ & $<0.001$ & 0.007 & $<0.001$ & $<0.001$ \\
\hline Serum uric acid, mg/dL & $5.12 \pm 1.32$ & $5.52 \pm 1.22$ & $6.04 \pm 1.37$ & $<0.001$ & 0.059 & $<0.001$ & 0.002 \\
\hline C-reactive protein, mg/L & $0.5(0.3-1.3)$ & $0.6(0.3-1.3)$ & $1.4(0.7-4.1)$ & $<0.001$ & 0.988 & 0.006 & $<0.001$ \\
\hline \multicolumn{8}{|l|}{ Medical history } \\
\hline Ischemic stroke/TIA, n (\%) & $9(18.4)$ & $48(30.0)$ & $38(40.0)$ & 0.026 & 0.110 & 0.009 & 0.102 \\
\hline Peripheral artery stenosis, $n$ (\%) & $0(0)$ & 19 (11.9) & $17(17.9)$ & 0.007 & 0.011 & 0.002 & 0.182 \\
\hline Hypertension, n (\%) & $33(67.3)$ & $118(73.8)$ & $81(85.3)$ & 0.031 & 0.432 & 0.020 & 0.053 \\
\hline Hyperlipidemia, $n$ (\%) & $35(71.4)$ & $137(85.6)$ & $88(92.6)$ & 0.003 & 0.023 & 0.001 & 0.093 \\
\hline \multicolumn{8}{|l|}{ Medications taken } \\
\hline ACEIs/ARBs, $n(\%)$ & $20(40.8)$ & $83(51.9)$ & $59(61.2)$ & 0.046 & 0.175 & 0.015 & 0.112 \\
\hline Statins, n (\%) & $34(69.4)$ & $152(95.0)$ & $88(92.6)$ & $<0.001$ & $<0.001$ & $<0.001$ & 0.437 \\
\hline Diuretics, n (\%) & $5(10.2)$ & $17(10.6)$ & $22(23.2)$ & 0.015 & 0.993 & 0.059 & 0.007 \\
\hline Proton pump inhibitors, n (\%) & $2(4.1)$ & $32(20.0)$ & $28(29.5)$ & 0.002 & 0.008 & $<0.001$ & 0.085 \\
\hline
\end{tabular}

LTA-AA Light transmission assay with arachidonic acid, eGFR Estimated glomerular filtration rate, PLT Platelet count, MPV Mean platelet volume, TIA Transient ischemic attacks, ACEls Angiotensin converting enzyme inhibitors, ARBs Angiotensin receptor blockers

To date, few studies have been conducted regarding the role of renal function on platelet reactivity. Conflicting results were reached, and most of them were conducted among patients receiving clopidogrel in association with aspirin [14-17]. However, there is evidence of overlap in the antiplatelet effects of aspirin and P2Y12 antagonist [11]. Regarding patients receiving aspirin monotherapy, results from previous studies were also inconsistent. Using the same technology (LTA-AA) in 169 patients with coronary artery disease, Blann et al. found that patients with aspirin resistance had lower eGFR than patients who were sensitive to aspirin [18]. Their data pointed to an association between worsening renal function and aspirin resistance, which was in line with our study. However, Würtz et al. reported that renal function did not correlate with platelet aggregation evaluated by multiple electrode aggregometry or the VerifyNow [19]. These conflicting results may be due to differences in the test methods of platelet reactivity or the inclusion criteria. The underlying mechanism of platelet hyperactivity in patients with impaired renal function might be related to chronic low-grade inflammation, vascular injury [20] and the accumulation of uremic toxins, such as indoxyl sulfate [21] and homocysteine [22]. Furthermore, pre-activation of platelets and platelet turnover [23] also play roles in the pathogenesis of insufficient platelet inhibition by aspirin in patients with impaired renal function.

Besides the impact of renal function, the mechanisms of HTPR are probably multifactorial. Previous studies have specifically addressed the relation between age and HTPR [9, 24-26]. Bobescu et al. reported that low response to aspirin was significantly correlated with age older than 65 years [27]. In our study, all enrolled patients are over 60 years old. There was a positive correlation between age and platelet aggregation rate. Age was 
a univariate predictor of HTPR, although this dropped out in a multivariate analysis. Future detailed mechanistic research is needed to investigate the relationship of platelet changes with aging and the pathophysiological basis of the antiplatelet response. Elderly patients also represent a category where other factors, such as low body weight, comorbidities or drug combination, have an intrinsic high risk of bleeding [28]. At present, antiplatelet strategies in elderly patients with ASCVD should be cautiously driven by an individualized approach, balancing thrombotic and bleeding risk.

Drug interactions have also been implicated as a potential mechanism of HTPR. PPIs are usually prescribed to patients receiving antiplatelet therapy to decrease the risk of upper gastrointestinal bleeding. Acid suppression with PPIs can increase the potential for mucosal esterases to hydrolyze aspirin to its inactive form. A reduction in gastric absorption results in an increased drug load within the small intestine, where hydrolysis by esterases prior to absorption may reduce bioavailability [29]. This could explain the finding in our study that PPI medication was more common in the HTPR group. Nevertheless, the current guidelines on cardiovascular disease are in favor of PPI prescription in those who are at risk of gastrointestinal bleeding, with the additional benefit that a reduction in dyspepsia may improve adherence [30,31]. It is worth noting that platelet reactivity should be monitored in these patients.

\section{Limitations}

There were several limitations in this study. First, the present data were observational, with all the inherent limitations of a retrospective analysis. We did not have baseline pretreatment data for platelet function as that would not have been feasible with this particular study design. Prospective or interventional investigations should be conducted in the future. Some clinical and biological parameters were intertwined and inevitable. Larger trials with subgroup analysis and matched-pair analysis are needed. Second, we only used LTA-AA tests as a surrogate measure of aspirin response, rather than specific assessment of its effect on the therapeutic target (i.e., thromboxane B2).

\section{Conclusions}

Among elderly patients receiving antiplatelet therapy with aspirin for secondary prevention of ASCVD, advanced age was correlated with insufficient antiplatelet effects of aspirin. A significant relationship between HTPR and impaired renal function was also observed. Larger trials are needed to assess the clinical impact of this finding and investigate the optimal antithrombotic regimen in elderly patients.

\section{Abbreviations}

ACEl: Angiotensin converting enzyme inhibitor; ARB: Angiotensin receptor blocker; ASCVD: Atherosclerotic cardiovascular disease; COX: Cyclooxygenase; eGFR: Estimated glomerular filtration rate; HTPR: High on-treatment platelet reactivity; LTA-AA: Light transmission aggregometry with arachidonic acid; MPV: Mean platelet volume; PLT: Platelet count; PPI: Proton pump inhibitor; ROC: Receiver operating characteristic; TXA2: Thromboxane A2

\section{Acknowledgements}

Not applicable.

\section{Authors' contributions}

WYL: study design, obtaining funding, acquisition of data, interpretation of data, statistical analysis, drafting of the manuscript. PZ: study design, acquisition of data, interpretation of data, statistical analysis. MLL: study design, obtaining funding, interpretation of data, administrative support, revision of the manuscript, and supervision of the whole study. All authors read and approved the final manuscript.

\section{Funding}

This study was supported by the Research Foundation of Peking University First Hospital [2017QN23], the National Key Research \& Development Project of China [2016YFC1301304] and the National Science \& Technology Support Program of China [2012BAl37B05]. The funding body had no role in the design of the study and collection, analysis, and interpretation of data and in writing the manuscript.

\section{Availability of data and materials}

The datasets used or analysed during the current study are available from the corresponding author on reasonable request.

\section{Ethics approval and consent to participate}

This study was conducted in accordance with the Declaration of Helsinki, and the protocol was approved by the Ethical Review Committee of Peking University First Hospital. Administrative permissions from the Ethical Review Committee of Peking University First Hospital were required to access the raw data. The need for consent was waived because of the retrospective data.

\section{Consent for publication}

Not applicable.

\section{Competing interests}

The authors declare that they have no competing interests.

Received: 21 August 2020 Accepted: 11 January 2021

Published online: 22 January 2021

\section{References}

1. Stone NJ, Robinson JG, Lichtenstein AH, Bairey MC, Blum CB, Eckel RH, et al. ACC/AHA guideline on the treatment of blood cholesterol to reduce atherosclerotic cardiovascular risk in adults: a report of the American College of Cardiology/American Heart Association task force on practice guidelines. J Am Coll Cardiol. 2014;63(25 Pt B):2889-934.

2. Lin TT, Lai HY, Chan KA, Yang YY, Lai CL, Lai MS. Single and dual antiplatelet therapy in elderly patients of medically managed myocardial infarction. BMC Geriatr. 2018;18(1):86.

3. Bazargani YT, Ugurlu M, de Boer A, Leufkens H, Mantel-Teeuwisse AK Selection of essential medicines for the prevention and treatment of cardiovascular diseases in low and middle income countries. BMC Cardiovasc Disord. 2018;18(1):126.

4. Patrono C, Coller B, Dalen JE, FitzGerald GA, Fuster V, Gent M, et al. Plateletactive drugs : the relationships among dose, effectiveness, and side effects. Chest. 2001;119(1 Suppl):395-63S.

5. Patrono C. The multifaceted clinical readouts of platelet inhibition by lowdose aspirin. J Am Coll Cardiol. 2015;66(1):74-85.

6. Marcucci R, Paniccia R, Antonucci E, Gori AM, Fedi S, Giglioli C, et al. Usefulness of aspirin resistance after percutaneous coronary intervention for acute myocardial infarction in predicting one-year major adverse coronary events. Am J Cardiol. 2006;98(9):1156-9. 
7. Mayer K, Bernlochner I, Braun S, Schulz S, Orban M, Morath T, et al. Aspirin treatment and outcomes after percutaneous coronary intervention: results of the ISAR-ASPI registry. J Am Coll Cardiol. 2014;64(9):863-71.

8. Pettersen AA, Arnesen $H$, Seljeflot I. A brief review on high on-aspirin residual platelet reactivity. Vasc Pharmacol. 2015;67-69:6-9.

9. Gremmel T, Steiner S, Seidinger D, Koppensteiner R, Panzer S, Kopp CW. Adenosine diphosphate-inducible platelet reactivity shows a pronounced age dependency in the initial phase of antiplatelet therapy with clopidogrel. J Thromb Haemost. 2010;8(1):37-42.

10. Verdoia M, Pergolini P, Nardin M, Rolla R, Tonon F, Kedhi E, et al. Impact of aging on platelet reactivity in diabetic patients receiving dual antiplatelet therapy. J Thromb Thrombolysis. 2019;48(3):413-21.

11. Warner TD, Nylander S, Whatling C. Anti-platelet therapy: cyclo-oxygenase inhibition and the use of aspirin with particular regard to dual anti-platelet therapy. Br J Clin Pharmacol. 2011;72(4):619-33.

12. Zhang JW, Liu WW, McCaffrey TA, He XQ, Liang WY, Chen XH, et al. Predictors of high on-aspirin platelet reactivity in elderly patients with coronary artery disease. Clin Interv Aging. 2017;12:1271-9.

13. Levey AS, Coresh J, Greene T, Stevens LA, Zhang YL, Hendriksen S, et al. Using standardized serum creatinine values in the modification of diet in renal disease study equation for estimating glomerular filtration rate. Ann Intern Med. 2006;145(4):247-54.

14. Polzin A, Dannenberg L, Sansone R, Levkau B, Kelm M, Hohlfeld T, et al. Antiplatelet effects of aspirin in chronic kidney disease patients. J Thromb Haemost. 2016;14(2):375-80.

15. Angiolillo DJ, Bernardo E, Capodanno D, Vivas D, Sabate M, Ferreiro JL, et al. Impact of chronic kidney disease on platelet function profiles in diabetes mellitus patients with coronary artery disease taking dual antiplatelet therapy. J Am Coll Cardiol. 2010;55(11):1139-46.

16. Feng ZM, Lin YQ, Deng BQ, Shu XR, Ke X, Nie RQ. Pharmacodynamic changes of platelet reactivity status in patients with chronic kidney disease after coronary artery stenting. Biomed Pharmacother. 2019;113:108773.

17. Barbieri L, Pergolini P, Verdoia M, Rolla R, Nardin M, Marino P, et al. Platelet reactivity in patients with impaired renal function receiving dual antiplatelet therapy with clopidogrel or ticagrelor. Vasc Pharmacol. 2016;79:11-5.

18. Blann AD, Kuzniatsova N, Velu S, Lip GY. Renal function and aspirin resistance in patients with coronary artery disease. Thromb Res. 2012; 130(3):e103-6.

19. Wurtz M, Wulff LN, Grove EL, Kristensen SD, Hvas AM. Influence of renal function and platelet turnover on the antiplatelet effect of aspirin. Thromb Res. 2012;129(4):434-40.

20. Landray MJ, Wheeler DC, Lip GY, Newman DJ, Blann AD, McGlynn FJ, et al. Inflammation, endothelial dysfunction, and platelet activation in patients with chronic kidney disease: the chronic renal impairment in Birmingham (CRIB) study. Am J Kidney Dis. 2004;43(2):244-53.

21. Yang K, Du C, Wang X, Li F, Xu Y, Wang S, et al. Indoxyl sulfate induces platelet hyperactivity and contributes to chronic kidney disease-associated thrombosis in mice. Blood. 2017;129(19):2667-79.

22. Verdoia M, Rolla R, Negro F, Tonon F, Pergolini P, Nardin M, et al. Homocysteine levels and platelet reactivity in coronary artery disease patients treated with ticagrelor. Nutr Metab Cardiovasc Dis. 2020; 30(2):292-9.

23. Gremmel T, Muller M, Steiner S, Seidinger D, Koppensteiner R, Kopp CW et al. Chronic kidney disease is associated with increased platelet activation and poor response to antiplatelet therapy. Nephrol Dial Transplant. 2013; 28(8):2116-22

24. Verdoia M, Pergolini P, Rolla R, Nardin M, Schaffer A, Barbieri L, et al. Advanced age and high-residual platelet reactivity in patients receiving dual antiplatelet therapy with clopidogrel or ticagrelor. J Thromb Haemost. 2016; 14(1):57-64.

25. Faggioni M, Redfors B, Crowley A, Claessen BE, Farhan S, Mastoris I, et al Comparison of age ( $<75$ years $V s>/=75$ years) and platelet reactivity to the risk of thrombotic and bleeding events after successful percutaneous coronary intervention with drug-eluting stents (from the ADAPT-DES study). Am J Cardiol. 2020;125(5):685-93.

26. Silvain J, Cayla G, Hulot JS, Finzi J, Kerneis M, O'Connor SA, et al. High onthienopyridine platelet reactivity in elderly coronary patients: the SENIORPLATELET study. Eur Heart J. 2012;33(10):1241-9.

27. Bobescu E, Covaciu A, Rus H, Radoi M, Badea M, Moga SN, et al. Correlation of cardiovascular risk factors and biomarkers with platelet reactivity in coronary artery disease. Am J Ther. 2019;26(5):563-9.
28. Afilalo J, Alexander KP, Mack MJ, Maurer MS, Green P, Allen LA, et al. Frailty assessment in the cardiovascular care of older adults. J Am Coll Cardiol. 2014;63(8):747-62

29. Floyd CN, Ferro A. Mechanisms of aspirin resistance. Pharmacol Ther. 2014; 141(1):69-78.

30. Agewall S, Cattaneo M, Collet JP, Andreotti F, Lip GY, Verheugt FW, et al. Expert position paper on the use of proton pump inhibitors in patients with cardiovascular disease and antithrombotic therapy. Eur Heart J. 2013;34(23): 1708-13 1713a-1713b.

31. Knuuti J, Wijns W, Saraste A, Capodanno D, Barbato E, Funck-Brentano C, et al. 2019 ESC guidelines for the diagnosis and management of chronic coronary syndromes. Eur Heart J. 2020;41(3):407-77.

\section{Publisher's Note}

Springer Nature remains neutral with regard to jurisdictional claims in published maps and institutional affiliations.
Ready to submit your research? Choose BMC and benefit from:

- fast, convenient online submission

- thorough peer review by experienced researchers in your field

- rapid publication on acceptance

- support for research data, including large and complex data types

- gold Open Access which fosters wider collaboration and increased citations

- maximum visibility for your research: over $100 \mathrm{M}$ website views per year

At BMC, research is always in progress.

Learn more biomedcentral.com/submissions 